\title{
The psychosocial impact of exercising with epilepsy: A narrative analysis
}

\author{
Sarah S. Collard ${ }^{\text {ab }}$; Caroline Marlow ${ }^{\text {ac }}$ \\ a'University of Roehampton, Whitelands College, Holybourne Avenue, London, SW15 4JD, \\ England, United Kingdon
}

\section{Corresponding author: Sarah Collard}

b scollard@bournemouth.ac.uk; Present address: Bournemouth University, Faculty of Health and Social Sciences, Royal London House, Christchurch Rd., Bournemouth, BH1 3LT

${ }^{c}$ caroline@landmconsulting.co.uk; Present address: L \& M Consulting www.landmconsulting.co.uk

\begin{abstract}
:
Research has presented the benefits of and barriers to exercise for people with epilepsy through quantitative means. However, individual experiences through qualitative investigations have been absent. This research will present the narratives of people with epilepsy exercising over time and as a result, develop further understanding of the psychosocial impact of exercising with epilepsy. Four interviews were conducted over the course of one year (one every three to four months) with four participants (aged 23-38 years) who varied in seizure type and control (16 interviews in total). A narrative analysis was used to analyze their exercise experiences. Results showed that exercise creates a positive effect on psychological and physical well-being. However, prevention from exercise as a result of medical advice or re-current seizures can create negative effects such as social isolation, anxiety, lack of confidence, frustration, and anger. Adaptations of decreasing exercise intensity level and partaking in different physical activities are techniques used to lessen the negative impact and maintain an exercise routine. Time was shown to be an important factor in this adaptation as well as portrayed the cyclical responses of negative and positive emotions in regards to their exercise life. These findings provide valuable insight into the psychosocial benefits of and barriers to exercising with epilepsy, and draw attention to the individual differences in how a person with epilepsy copes with uncontrolled seizures and their impact on his/her exercise routine. This knowledge can lead to future research in exploring how a person with epilepsy can overcome these barriers to exercise and encourage more people with epilepsy to enjoy the benefits of exercise.
\end{abstract}

\section{Key Words:}

-Epilepsy; Exercise; Adaptation; Qualitative; Quality of life; Psychological

\section{Highlights:}

- Qualitative insight into exercising with epilepsy

- Exercise is felt to be beneficial to overall physical and psychological well-being.

-Adaptation methods increase the ability to maintain an exercise routine.

-Time is a factor in coping with the impact of epilepsy upon one's exercise routine. 


\section{Introduction}

For most people with epilepsy, physical activity has been shown to have positive effects on seizure control and personal well-being [1]. Recently, the International League Against Epilepsy (ILAE)'s task force on sports and exercise promoted these benefits and provided clinical advice on how to exercise safely in regards to level of seizure control [2]. However, despite the physical and mental benefits of physical activity, exercise is still not a regular occurrence for people with epilepsy [3]. The main reasons reported for inactivity are the fear of the seizure occurring $[4,5]$, fear of seizure-related injuries [6], and being inadequately informed about the possibilities of playing sports [7]. As a potential result of this inactivity, social isolation, low self-esteem, weight gain, and depression are commonly found among people with epilepsy $[7,8]$.

The abundance of research exploring the benefits of and barriers to exercise for people with epilepsy has been primarily quantitative and medico-scientific $[4,8,9,10]$, leaving an omission in our understanding of the first-hand exercise experiences of people with epilepsy. Therefore, through the use of narrative inquiry, this research aims to present the psychosocial impact of exercising with epilepsy over time. Providing first-hand accounts of the emotional response to the impact of epilepsy on exercise routine of the person with epilepsy, these narratives provide the multidimensional impact of exercising with epilepsy over one year, and subsequently allow further insight into the barriers and benefits of exercising with epilepsy. In turn, this research aims to encourage the development of methods for people with epilepsy to overcome such barriers and allow more people with epilepsy to benefit from physical activity.

\subsection{Narrative inquiry}

Using a social constructionist philosophy, narrative inquiry was chosen as it has been shown to promote a heightened understanding to a subject matter that is limited through the use of quantitative means $[11,12,13,14]$. Described as the 'linguistic form uniquely suited for displaying human existence as situated action' [13, p.5], narratives use language as the tool to make an experience meaningful [15]. In the use of language, multiple discourses from one's experiences can be expressed, presenting the shift and changes in subjectivity, rather than a stable, or fixed self [16]. As time has been shown to be significant to narrative construction $[15,17]$, it is of importance to this research to also consider the effect of time on the exercise experiences of the person with epilepsy.

\section{Method}

Participants were recruited through the Epilepsy Action UK research database and an epilepsy medical center in southern England. The three criteria for participants were the following: 1) epilepsy was the participant's main condition [18]; 2) age was 18 years and/or older; and 3) participant exercised at least three times a week, or would do so, were they not hindered by their epilepsy. These criteria were to ensure that exercise was important to the participant, as well as each having an epilepsy diagnosis [3]. Exercise type and seizure type were of no consequence to recruitment, however, each was noted for future research 
purposes. Four participants were recruited following ethical approval from the University of Roehampton. As each participant remained throughout the research process, the depth of knowledge obtained was sufficient and, therefore, no further participants were recruited. Participants' anonymity was maintained through the use of pseudonyms.

\subsection{Interview process}

Four interviews over the course of one year (one every three to four months) were completed with each participant (16 interviews total). Interviews were semi-structured/conversational in nature to enable a 'conversation' with the person with epilepsy [19]. Questions of what and how, and not why, were used in order to focus on the individual's experience [20, 21]. The first interview opened with the question, "Describe your experiences of exercising with epilepsy" and was further developed through clarification and elaboration probes. Background questions were asked concerning exercise routine, family life, and work, as well as obtaining basic demographics. Questions for the subsequent interviews were developed through the themes identified and researcher reflection on earlier interviews. Interviews varied in time (lasting approximately an hour and a half to $4 \mathrm{~h}$ ), took place at locations that were chosen by and comfortable for the participant (e.g., university interview rooms and quiet coffee shops), and began after written and verbal consent were obtained. Personal diaries were supplied to the participants as a supplement to the four interviews and as a tool to add depth to their lived experience [22]. Although participants read segments of the diaries aloud during interviews, these were not separately analyzed as it was agreed at the start of the research process that the collection of the diaries was voluntary.

The researcher/participant relationship was based on trust and rapport, which resulted from earlier conversations via email and/or telephone, as well as general conversation prior to the start of the interview. As the main researcher had epilepsy, where appropriate, she was willing to share aspects of her exercise experiences with the participants in order to enhance the trust and rapport built with the participants [23]. For example, the participants were able to ask questions concerning the author's own experiences of exercising with epilepsy, thus sparking them to divulge more and become more relaxed within the interview environment.

Reflection is a key methodological step within qualitative research, allowing for preconceptions to be acknowledged [24]. In order to recognize any potential limitations and/or benefits to this research due to personal entanglement, multiple reflective steps were taken (e.g., self-interview (main researcher), memo writing, reflection journal, conversations with the co-author). These steps were taken with the aim of limiting the effect from personal experience upon conducting the interviews and the compilation of the narratives [24]. Although we acknowledge that we cannot limit all researcher effect, through reflecting throughout the course of the research, we were able to acknowledge this impact as well as view the positives of such an effect.

\subsection{Narrative analysis}

A narrative is defined as 'a complex genre that routinely contains a point and characters along with a plot connecting events that unfold sequentially over time and in space to provide 
an explanation or consequence' [25, p.2]. This research used a holistic-content approach to best bear witness to the person with epilepsy's story [11, 26, 27] because of how it views the complete 'story as a whole, contextualized in a culture and history, and attempts to grasp the overall pattern or guiding metaphors' [28, p.537]. Following interview transcription, narrative analysis began through the process of identifying themes and marking them in each margin. These themes were then organized in relation to overall importance of the individual's narrative, as well the connections to other relevant themes. The transcript was then re-read to confirm that no other themes were present [27]. Next, to provide a visual representation of the thematic connections, a thematic map was developed from the present themes [11]. Discussions with the co-author allowed for a more concrete thematic map and confirmation that the themes present reflected the interviews. The results presented below are the most common themes across each participant's narrative. Prior to presenting the findings, the background of each participant will be provided.

\subsection{Participants}

Gwen, 38, was diagnosed with complex partial seizures at age 11 and aimed to exercise at least three times a week. Choosing to mainly run and/or swim for exercise, Gwen discussed a constant frustration with barriers to exercise as a result of uncontrolled seizures. Currently not taking medication as she is trying to become pregnant, Gwen had intractable epilepsy with seizures occurring weekly. Married to a supportive husband, Gwen felt envious of others who were able to exercise as and when, leaving her with a feeling of a lack of control of her body.

Rose, 25, was diagnosed with tonic-clonic seizures a year prior to the interviews commencing, and has experienced two seizures in her life. Exercising approximately three to four times a week, her exercise type of choice was running or swimming. She expressed the benefits of exercise on her reduced feelings of stress and fatigue, yet also felt frustrated at her family and friends' lack of understanding of how her epilepsy impacted her life.

Maya, 23, has had simple partial seizures since she was a young child as a result of a brain tumor. Following surgery to remove the tumor at 3 years old, she became seizure-free, but at the age of 13, the seizures returned as a result of scar tissue build up within the brain. Depending on seizure activity, Maya competed in open water races and swam at least four times a week, both in a swimming pool and open water. Maya was passionate about swimming and was determined to be the first person with epilepsy to swim the English Channel.

Andrew, 28, was diagnosed with tonic-clonic seizures at age 18. Exercising at least four times a week, he participated in team rowing, swimming, and attended the gym. Andrew experienced seizures often during exercise. He discussed feeling very embarrassed and fearful of his epilepsy during and/or as a result of exercise, and felt stigmatized by a few members of his rowing team.

\section{Results}


The results over the course of one year presented a varied emotional response due to uncontrolled seizure activity negatively affecting each participant's exercise routine. Varying from cycles of negative emotions as a result of non-exercise, to promoting the benefits of exercise upon seizure activity and overall well-being, these narratives provide new insight into the psychosocial impact of exercise for people with epilepsy. Variables that compounded this emotional response included identity, inadequate medical advice, exercise type, social support, seizure frequency, and seizure type. The following will describe the psychosocial impact of exercising with epilepsy (effect of exercise, frustration, and anxiety) as well as the variables that helped formulate a positive and/or negative quality of life over the course of one year (seizure frequency, common physical activities, and social support).

\subsection{Effect of exercise:}

For each participant, exercise was one of the main methods used to increase physical and mental well-being. Participants were self-motivated to exercise to relieve mental stress, solidify athletic identity, and maintain their physical and mental health. The participants shared what exercise meant to them:

Swimming is not a sociable sport, swimming is where I live. I'm awake, I'm calm, I'm not thinking of anything but the lengths, the number of breaths, you know? I love swimming. I've never been so obsessed with swimming in my life. I love it. (Maya, Interview 2)

It's very important to me to keep fit. It always has been. When I was at school, I was really, really, really... fit! ... Like 2, 2 years ago ... it's a bit more ... "If you don't do exercise, that's fine". But now I'm so, so keen to keep fit 'cause I'm in my late 30s and I really don't want to [laughs], not do anymore exercise. (Gwen, Interview 1)

In this past year when I have been feeling rubbish, I think exercise has been one of the things that, you know not THE one, but one of the things that sort of helped me.... It makes me feel better as well because it's not, ... If I didn't do anything like that, some nights I'd just go to work and come home, have dinner, go to bed, go to work... So it's nice to have that something extra, because it's like a social outlet or it does make you feel better or it does make you forget about the day... I've started to push myself too much in the gym and I will feel, like really tired afterwards, but then feel a bit better later. But then mostly exercise makes me feel better straight away, bit more energized... and I never actually felt twitchy in my head during exercise. (Rose, Interview 1)

For Andrew, the importance of sport was shown throughout the four interviews. However, in our second interview, he was remarkably different, less upbeat and more downcast. This was the result of being told to stop exercising by his neurologist. In our third interview, his low emotional state had lifted as a result of his epilepsy nurse encouraging exercise and his brother offering support. This caused him to express the positive feelings of how it feels to exercise again:

Feels awesome! Might go running when I go back. I'm trying to be as active as possible, and every time I do it, I'm taking those words my brother said, "Take your anger out on it" ... "Take that idea, take that theory and you'll feel a lot better." And, 
it seems to work... I tried running last year, and I ran for a week, and yeah, nothing. And now, I run in a 10-year-old pair of trainers, for a month! Consistently, four times a week, and I love it! I think it's just brilliant! ... At the moment I try to optimize myself, ... I'm enjoying it too much. (Andrew, Interview 3)

\subsection{Frustration:}

Frustration was a key emotion that differed in intensity over time and across participants. However, one commonality among the participants was the frustration at the inability to exercise when they so desired.

I do my best to really try and keep fit and I think, rather than me, my exercise dominating what I'm doing, it's my epilepsy that seems to be making my decisions when I can exercise. Which I find very, very frustrating. ... I'd love to say I'm going out for a run tomorrow, but you know, if I have a seizure, I can't do that. I don't know whether I will be well tomorrow, that's what I feel frustrated about. I can't make any plans... But I'm also in a catch 22 situation 'cause I'm also really quite determined. I get really, I can't win, when I'm prevented from doing it. It's very frustrating. (Gwen, Interview 1)

Although Maya was not overly frustrated by her epilepsy preventing exercise, as she stated that she possibly would swim through a seizure, she did express frustration in her inability to swim when and where she wanted due to her driving restriction:

I get really edgy if I don't swim. I get really frustrated.... I hate that I can't just drive and just get home. The same from swimming... If I could get to swimming events on my own... But I don't, I have to rely on everyone. (Maya, Interview 2)

This frustration was compounded by others' comments as well as their own physical limitations. Andrew expressed his frustration at being told to stop exercising:

Umm, like everyone has told me to stop. And it's annoying. It's like, I can't. [long pause] I've loved sport since I was a kid, and I'd always played football, and always played tennis, and always been part of team sports, and if it's a new thing, I'd want to take part in it. And being told not to isn't [laughs], just isn 't... [something I'm prepared to do]. (Andrew, Interview 1)

Andrew's frustration also manifested as a result of the lack of information and stories of people with epilepsy experiencing what he is going through:

Well there wasn't anything umm, to do with it, ... All the websites just said... "Don't swim, don't go near water sports, don't do this." "If you're riding a bike, make sure you've got somebody behind you, blah, blah blah." All the obvious stuff you would think of. Not, "Oh there's a group for this, there's a group for that." No one suffering from it, putting their story out there, and an expert coming back and saying, "Totally agree with you but, perhaps you should try this." Whereas the American website has massive forums, explaining their stories, and allowing experts to come back. And, there's people out there like you! As soon as I read them, I was like, "Bloody hell, there's a continent on the other side of the Atlantic with loads of people suffering 
from it. And in Great Britain no one, seems to have the problems I've got!" (Andrew, Interview 1)

\subsection{Anxiety:}

Anxiety was commonly linked to their own, as well as others, fears of exercising safely with their seizures. Prior to our third interview, Rose had a seizure while running, causing her to become more anxious of exercising:

I hate that sort of anxious feeling, of like, "Am I going to have a fit?" I struggle to get out of it... If I have all that anxiety, it doesn't help. But in the end what I think, it's [epilepsy] always going to be there. Regardless of how long it's been, it's [seizure] always going to be a possibility. ... Umm, just generally a lot more anxious... I also probably don't enjoy it [exercise] as much 'cause I'm getting anxious... I think partly for the reason I wasn't going out on my own is because of the fit [whispers fit]. (Rose, Interview 3)

As highlighted earlier (see 3.1, 3.2), Andrew's uncontrolled seizures and his neurologist's warning of exercise began to make him wary of his exercise routine. As his fear of having another seizure at rowing increased, his decision to follow his neurologist's advice also caused him to lose the social aspect of his exercise life:

It got to June, and I had to say to my rowing people, "Look I can't go on... I am almost endangering you by me being so worried all the time." And I'm being negative, and they were really good... But, it's like a... community that I kinda lost. (Andrew, Interview 2)

3.4 Increased seizure frequency leading to adaptation:

Seizure frequency varied amongst the participants. Maya (at least one per week) and Gwen (at least one every two weeks) had the highest frequency, while Andrew (two to four a year) and Rose (one a year) had the least. For Gwen, Andrew, and Rose, the higher the seizure frequency, the more negative of an impact it had upon the participant's exercise frequency and resultant emotional response. This was shown, as illustrated above (see 3.2, 3.3), through Gwen's constant frustrations as a result of recurring seizures preventing exercise; Andrew's newly developed fear of a vigorous effort during exercise; and Rose's new worry of exercising as a result of having a seizure. On the other hand, Maya seemed to deny the impact of a high seizure frequency and always aimed to maintain her usual swimming routine, despite having recurrent seizures.

Sometimes I think mentally you can control it anyway. I don't know. Cause I think sometimes with my fits, I might go like, I might feel it. Other times I'm not, I might just ignore it and don't concentrate on it and therefore it's not, I can't feel it as much? My mind is pre-occupied with something else. I kinda swam through mine, I was kinda just a little bit...blind. (Maya, Interview 1)

Over time, as shown by Gwen, Andrew, and Rose, the increase in recurrent seizures caused the participants to adapt their exercise intensity and type to allow for a more consistent exercise routine. Gwen began to swim rather than run or attend the gym; Andrew began to do 
exercises in his home, rather than at the gym or rowing; and Rose became more cautious of running alone or when she was fatigued. For Maya, shifts eventually occurred in her recognition as to when it was worthwhile to push through fatigue, compared with just taking a rest day.

I think the exercise type [swimming] is much more relaxing for me, but I think the intensity, when I go for a 30 or 40 minute swim, even though I feel like I've done some vigorous exercise, it's not the same feeling as when I came out of the gym when I just felt drained! Exercise is supposed to make you feel better afterwards. I didn't really get that so much with the gym. And I was pretty much guaranteed a seizure the following day. With swimming I don't get that. ... I feel more in control, that's the biggest thing. I feel, I keep using the word relaxed, but I do. I don't feel like I'm compensating for the fact that it's not as strenuous on the body as a gym exercise... I don't feel like I'm compromising. It doesn't feel like a chore. You know with some exercises you feel like, "Oh, I've gotta go for a run." I actually just really enjoy doing it. I don't really think about my seizures per se. I think occasionally it pops into my mind, but I get so invested into my exercise and the effect it's having on me and how much I'm enjoying it, that it doesn't really come into the equation.

(Gwen, Interview 2)

Well, it (having another seizure) did worry me a bit actually... in terms of like, going out running on my own, cause I always go out on my own. I've been out once [after my recent seizure] and sort of saying to my sister, "I'm going to stick to main roads and I'm going to go here, and if I don't come back..." [little laugh] ... Sometimes I get home from work and I think, "Oh, I want to go out for a run." I think I'll be fine, I think it's just getting back into it and being more sensible about when I go. ... But it [the seizure] did worry me a bit, you know; put me off properly going on my own as much. I try to go with somebody now. (Rose, Interview 3)

I'm always tired...I know if I slept, and I'm not tired, I can do anything! But when I'm tired, I can't do anything ... mhhm [nodding yes] ... But I do notice, when I'm stupidly tired, I find it very, very hard [to exercise]. And I almost convince myself, "[Maya] it's ok". And I do stop myself [from exercising] when it's that bad. But I do feel really guilty. Might as well get my sleep and do a harder session the next day. (Maya, Interview 3)

Although Andrew did adapt his exercise type and intensity, this caused symptoms of depression and increased social isolation.

So I've gone completely from any like, social, like the gym... I left the gym and taken it to my house, and started, I guess I picked up sports where you can't injure yourself as much as possible. If that makes sense? ... My sports, when I was younger, were BMXing and downhill mountain biking, and now it's gone to lifting a weight in a bedroom. It's kinda like... but, if that's what it has to be, that's what it has to be until there's a cure... My stress levels have gone up because I'm not exercising. (Andrew, Interview 2)

Similarly, Gwen also exhibited adaptation (e.g., swimming rather than running), however, this change in exercise routine did not effectively ease her emotional state. Instead, Gwen 
seemed to continue to want to increase her exercise intensity, which as a result, maintained her frustration levels.

I swim quite energetically at the moment, I don't like just going and doing, a calm swim. Which is sometimes quite nice to do, but I tend to do it quite vigorously... I'm quite hard on myself because I feel I should be doing at least twice a week, and then it doesn't happen, so I feel like I have to over compensate for that, and then that's when it's [have a seizure] more likely to happen, I suppose. (Gwen, Interview 2)

However, over time, Gwen desired to reach an equilibrium where her seizures would not dictate her exercise routine and she would benefit rather than feel frustrated from her exercise routine.

\subsection{Common physical activities:}

The most common physical activities were running and swimming. Over the course of the year, swimming was the one activity that the participants felt more relaxed during, as well as feeling that it decreased their seizure frequency. Pilates and yoga were also discussed as physical activities the participants used to keep active. However, they were not seen as "vigorous" enough for some of the participants.

I've always done Yoga and Pilates, which is just something, not much, just relaxing. But never ever worried about having a fit when I'm doing that. Which is interesting. It's not physically demanding, is it? (Rose, Interview 4)

\subsection{Social support/medical advice:}

The social support perceived by the participants was mixed, with messages ranging from encouragement to exercise, to fear for their well-being. This was noted not only through the participants' family members and friends, but also the General Practioner and/or neurologists' exercise advice.

I was told by my GP, just when I was feeling so down on that medication, that exercise, should, would... help. But the neurologist, no, nothing. ... My dad likes me to exercise. I don't know if he just doesn't connect the exercise with the tired, I think he connects more tiredness with not sleeping... I think I'd struggle if I was told to stop exercising. I probably would exercise anyway, to be honest... I don't know...

(Rose, Interview 1)

I think... If I run with my husband, then, uh, ... yeah, I guess I feel a bit more supported. ... If somebody's with me, you know running with me, then I have that added security in the case that if something did happen, then that's fine. But it doesn't stop me from doing it on my own. If I did an hour's run, or an hour and a half's run with him, if it's particularly strenuous, I don't think it would stop me necessarily having a seizure the following day, just because I had someone with me at the time... He doesn't offer [to go on a run] in terms of feeling insecure about me going on my own, no... not at all. No, he knows I can go off on my own. He has no problems at all. He has got confidence in me. Knows I'll be fine, I'll be ok. In fact, if things were to happen, it's usually post-exercise anyway. (Gwen, Interview 1) 
After Andrew was told to stop exercising by his neurologist (prior to the second interview), he went into a negative emotional spiral:

I took my brother along [to the neurologist's office] and my girlfriend along for a bit of support and I got quite angry. And she [the neurologist] said, "Look, you could put people in [danger]. You could get annoyed by this, blah, blah, blah." Umm, football I had to give up because it's in * and travelling there and back is dangerous, so she said, "Give that up." Two things, sporty things in my life that I really looked forward to each week, three sessions a week, that I really liked, have completely disappeared. ... I think I've been scared a lot this year by, not by myself, but by my friends and family and stuff about my life and the risks I'm taking. But then, what do you do if you don't do anything? What do you do? It's a more boring life? Sort of all said, "You're 28 , you're going out on a row boat, you're swimming on your own, you're going to the gym on your own. You're doing this and you shouldn't really be doing that." It makes me think, "Yeah, maybe if I do go swimming or the gym on my own, maybe I should go tell someone?" But I don't want to tell someone that I'm swimming because then I have got to have some idiot watch me swim, and I don't want that. (Andrew, Interview 2)

The social support effect was also presented through the view of being stigmatized by others for their epilepsy. In regards to enacted stigma, Andrew shared the instances in which his epilepsy drew negative attention from others:

You can see a few people are worried by it and don't want to talk to me and don't want to be next to me cause, in the circuit training we go round and round from point to point. And you can see their hesitance being in front of me or being behind me, 'cause they will be the person, the first person to come to blows, so to... and... [laughs as he says the sentence] they won't speak to me for the rest of the evening.

(Andrew, Interview 1)

Maya also felt stigmatized in regards to coaches and officials allowing her to be pushed to the level that she desired:

I went onto a long distance [swimming] camp in March, and they [coaches] didn't push me because they were scared of me fitting, and I had to do loads of medical things to let me go... and they were scared to push me. ... I don't think I'm going to die swimming it [The Channel], you know... just because epileptics shouldn't swim The Channel... I just think it's because they [officials] think epileptics shouldn't do stuff like that. "Because epilepsy's stress-related, surely The Channel's going to be stressrelated!" ... It's just annoying that they're not helping me out, they're making it harder. They shouldn't be, they should just... a lot of people get scared when they hear that word.... (Maya, Interview 1)

\section{Discussion}

These narratives have presented first-hand insights into the positive and negative impact of epilepsy on the person with epilepsy's physical and psychological well-being. Previous research produced evidence of the psychological benefits in relation to participation in physical activity, but also of a depressive effect due to the lack of exercise, fear to exercise, and denial of medical advice $[3,7,10 ; 30,31]$. This paper adds new connections and 
variables (e.g. adaptation, exercise importance and choice, social support, and stigma) that will be a contribution to current literature. The following will discuss the common psychosocial effects of exercise found within these narratives and their link to current literature.

First, the experiences of these participants highlighted the psychosocial benefits of exercise, allowing them to maintain a higher quality of life as a result of an increase in confidence, higher self-esteem, higher self-efficacy, relaxation and improved mental state. Participants explained that the more they exercised, the more they maintained their athletic identity, felt in control of their body, and felt less overall stress. Current epilepsy and exercise literature is in agreement with these findings $[2 ; 3,5,7,10,31,32,33,34]$. Progressing this research forward, it would be beneficial to present more voices of people with epilepsy and the benefits of exercise upon their overall well-being.

As consistent physical activity allowed the participants to experience the benefits of exercise on their overall well-being, the reduction or elimination of physical activity produced undesirable psychosocial effects. Examples of the negative side effects from the lack of exercise included symptoms of depression, lack of confidence, fear of safety whilst exercising, weight gain, social isolation, and low self-esteem. For Gwen, Maya, and Andrew, exercise was a key part of their identity, and as a result, was a factor in exacerbating these side effects. This link to identity has been largely absent from current literature and only recently has been shown with a link to epilepsy and exercise [5].

Frustration caused by being prevented from exercising was a key emotional response for these participants, and had not yet been exhibited in-depth within research [5]. Frustration was common amongst all the participants, as being 'held back' from exercise seemed to create a feeling of inability to control their exercise life, and to achieve valued exercise aims. Similar findings are seen within sport, injury, and illness literature [29, 35], and have only recently been presented within epilepsy and health literature [5, 14]. This frustration only seemed to be soothed by a consistent exercise regime, and would return once it was disrupted. This created a cyclical emotional impact on the participants and future research could explore ways of coping with this on-going disruption.

Although exercise maintenance was desired, fear was prevalent as an obstruction for the participants in their exercise lives. This finding of fear as an exercise deterrent is in accordance with current research $[1,4,7,8,10,30,31]$, however, the qualitative approach taken allowed for the diverse ways in which fear manifested itself to be revealed. Such manifestation included the fear that seizures could prevent Maya from achieving her end goal and would cause teammates to keep away from Andrew at the gym, as well as create the feelings of a loss of independence for Rose and Gwen. Further, it is evident from this research that these elements of fear go beyond being a basic barrier to exercise, but have a concrete impact on a person with epilepsy's quality of life.

In dealing with these emotional reactions, acceptance of physical limitations and adaptation of physical activity type/choice and intensity were found to ease strong negative reactions. 
Presenting new additions to the literature, adaptation methods to exercise are a key output of this research. Limiting exercise to certain contexts (e.g. after eating, not fatigued, feeling healthy, and decreased exercise intensity) and listening to their bodies were ways adaptation limited their seizures and enhanced the feeling of control. Andrew and Rose exhibited this more over time than Gwen and Maya. These results and current research encourages people with epilepsy to learn to listen to their body and exercise safely, thus allowing a more consistent exercise regime $[2,3,7,34]$, and subsequently lead to a reduction in negative emotional responses. Furthermore, as decreasing exercise intensity and frequency did cause a negative emotional response, research should explore ways for people with epilepsy to cope with these adaptations.

Linking to adaptation of physical activity, it was interesting to examine the exercise choices of each participant and how these changed over time. Not yet discussed within research as to the reasons a person with epilepsy chooses one activity over another, these narratives revealed that an exercise intensity level is key in regards to the choice of physical activity. As swimming and running were felt to be more worthwhile activities in regards to staying fit compared with activities like Pilates or yoga, it would be of interest to explore further methods in how people with epilepsy can safely partake in their chosen activity.

Social support ranged from a supportive family, friend, or team member, to a neurologist who recommended limiting exercise. Medical advice in maintaining exercise habits differed amongst the participants and created a barrier to exercise. Although recommendations to continue exercise for emotional benefit are prevalent in current epilepsy and exercise literature $[2,3,7,8,34,36,37]$, and were shown through recommendations to Rose and Gwen, it was interesting to witness the emotional effect of the differences in medical advice provided, as was shown through Andrew's narrative. This first-hand insight into advice provided by medical professionals as well as the support that is needed by people with epilepsy to maintain an exercise routine has yet to be presented within the literature.

Examining the difference between positive recommendations shown in research outputs and actual medical advice given should be further explored in order to increase physical activity levels for people with epilepsy. As current recommendations are to encourage physical activity [2], it is hoped that with more first-hand experiences being presented within research, medical professionals will be inspired to actively encourage exercise for people with epilepsy and therefore allow more people with epilepsy to feel confident that they can exercise safely.

Linked to social support, the impact of stigma upon a person with epilepsy was also shown within these results. Adding to current research on stigma for individuals living with epilepsy [38], these narratives provided examples of stigma within an exercise context. The unknown of epilepsy or fear of a person with epilepsy having a seizure caused Andrew to feel that his teammates were nervous around him and Maya to feel unfairly prevented from taking part in some swimming events. Previous research has shown glimpses of the stigmatic nature of epilepsy in regards to partaking in sports, fear of disclosure of one's epilepsy to teammates, and the positive impact of athletic role models for people with epilepsy [39]. However, these narratives have provided further acknowledgement that stigma remains a barrier and can negatively impact a person with epilepsy's participation in physical activity. 
Finally, the influence of time was an important factor that played a large part of this new addition to literature. Time created cyclical responses of negative and positive emotions for the participants as well as the beginnings of acceptance and adaptation. This has recently been shown within research $[5,14]$, but would benefit from further exploration over a longer course of time.

This research is the first of its kind, to our knowledge, to offer insight into the psychosocial impact of exercising with epilepsy over time. Providing an in-depth exploration created a detailed account of never before discussed adaptation methods, the impact of medical advice upon the person with epilepsy, and the emotional responses to exercising with epilepsy. As with any research, there were limitations. First, as this was an in-depth narrative study, few participants were studied and therefore these results cannot be generalized for every individual with epilepsy. However, although generalization cannot occur, through providing these individuals' stories, it has presented a kaleidoscope of experiences which occur for people with epilepsy. Second, the criteria allowed for a close exploration of individuals with epilepsy who already had an acknowledgement of exercise importance within their lives; this may not be true for every person with epilepsy. However, our results do acknowledge the psychosocial impact of epilepsy on exercise for people with epilepsy and provides a path for further investigation.

\subsection{Conclusion}

These narratives have furthered the current epilepsy literature by providing a voice to people with epilepsy with regard to their exercise experiences. Presenting the importance of time as a factor in psychosocial impact, new themes of a cyclical emotional response to exercise disruption, social support impact, as well as the benefits of different exercise activities, these narratives show the individual differences that exist between people with epilepsy who exercise. Such individuality has not been presented through the use of quantitative research and would benefit from further qualitative investigation. As a result of these findings, it is hoped that further exploration of the barriers to exercise and how they may be overcome will enable more individuals with epilepsy to exercise and enjoy a higher quality of life.

\section{Acknowledgements}

We would like to thank the participants for being so open and willing to discuss their stories and Prof. Edwin van Teijlingen who read a previous version of this paper. This work was supported by Epilepsy Action UK.

\section{References}

1. Nakken KO, Bjorholt PG, Johannessen SI, Loyning T, Lind E. Effect of physical training on aerobic capacity, seizure occurrence, and serum level of antiepileptic drugs in adults with epilepsy. Epilepsia 1990; 31(1): 88-94.

2. Capovilla G, Kaufman KR, Perucca E, Moshé SL, Arida RM. Epilepsia. 2016; 57(1):6-12. 
3. Dubow JS, Kelly JP. Epilepsy in sports and recreation. Sports Med 2003; 33(7): 499-516.

4. Steinhoff BJ, Neususs K, Thegeder H, Reimers, CD. Leisure time activity and physical fitness in patients with epilepsy. Epilepsia 1996; 37(12): 1221-27.

5. Scarfe SV, Marlow C. Overcoming the fear: an autoethnographic narrative of running with epilepsy. Qual Res Sport Exercise Health 2015;7(5):688-97.

6. Arida RM, Cavalheiro EA, da Silva AC, Scorza FA. Physical activity and epilepsy. Sports Med 2008; 38(7): 607-15.

7. Sirven J I. Epilepsy and exercising: Another brick in the wall? Epilepsy Beh 2009; 14: 1-2.

8. Nakken K O. Clinical research: Physical exercise in outpatients with epilepsy. Epilepsia 1999; 40(5): 643-51.

9. Arida RM, Scorza FA, Scorza CA, Cavalheiro EA. Is physical activity beneficial for recovery in temporal lobe epilepsy? Evidence from animal studies. Neurosci Biobehav Rev 2009; 33: 423-31.

10. Wong J, Wirrell E. Physical activity in children/teens with epilepsy compared with that in their siblings without epilepsy. Epilepsia 2006; 47 (3): 631-9.

11. Carless D, Sparkes AC. The physical activity experiences of men with serious illness: Three short stories. Psychol Sport Exerc 2008; 9: 191-210.

12. Oliver KL. A journey into narrative analysis: A methodology for discovering meanings. J Teach Phys Educ 1998; 17: 244-59.

13. Polkinghorne DE. Narrative configuration in qualitative analysis. Intern J Qual Stud Educ 1995;8(1): 5-23.

14. Collard SS, Marlow C. "It's such a vicious cycle": narrative accounts of the sportsperson with Epilepsy. Psych Sport Exerc 2016;24:56-64.

15. Crossley ML. Introducing narrative psychology. In: Milnes K, Roberts B, Horrocks C, editors. Narrative, memory, and life transitions, Huddersfield: University of Huddersfield; 2002, p.1-13.

16. Richardson L. New practices in qualitative research. Sociol Sport J 2000; 17: 5-20.

17. Carr D. Time, narrative and history. Bloomington: Indiana University Press; 1986.

18. Santiago MC, Coyle CP. Leisure-time physical activity and secondary conditions in women with physical disabilities. Disabil Rehabil 2004; 26(8): 485-94.

19. Dale GA. Existential phenomenology: Emphasizing the experience of the athlete in sport psychology research. Sport Psychol 1996; 10(4): 307-21.

20. Nesti M. Existential psychology and sport. New York: Routledge; 2004. 
21. Smith B, Sparkes AC. Narrative analysis and sport and exercise psychology:

Understanding lives in diverse ways. Psychol Sport Exerc 2009; 10: 279-288.

22. Dornelas EA. Existential issues, heart transplant, and end-stage cardiac disease. In: Dornelas EA, editor. Psychotherapy with Cardiac Patients: Behavioral Cardiology in Practice. Washington D.C.: American Psychological Association; 2008, p. 141-54.

23. Galvin RD. Researching the disabled identity: Contextualising the identity transformations which accompany the onset of impairment. Sociol Health Illn 2005; 27(3): 393-413.

24. Etherington K. Becoming a Reflexive Researcher. London: Jessica Kingsley Publishers; 2004

25. Smith B, Sparkes AC. Narrative inquiry in sport and exercise psychology: What can it mean, and why might we do it? Psychol Sport Exerc 2009; 10: 1-11.

26. Frank AW. The wounded storyteller: Body, illness, and ethics. Chicago: University of Chicago Press; 1995.

27. Lieblich A, Tuval-Mashiach R, Zilber T. Narrative research: Reading, analysis and interpretation. London: Sage; 1998.

28. Bleakley A. Stories as data, data as stories: Making sense of narrative inquiry in clinical education. Med Educ 2005; 39(5): 534-40.

29. Borkoles E, Nicholls AR, Bell K, Butterly R, Polman RCJ. The lived experience of people diagnosed with multiple sclerosis in relation to exercise. Psychol Health 2008; 23(4): 427-41.

30.Ablah E, Haug A, Konda K, Tinius AM, Ram S., Sadler, T, et al. Exercise and epilepsy: A survey of Midwest epilepsy patients. Epilepsy Behav 2009;14: 162-66.

31. Sturm JW, Fedi M, Berkovic SF, Reutens DC. Exercise-induced temporal lobe epilepsy. Neurology 2002; 59(8): 1246-48.

32. Conant KD, Morgan AK, Muzykewicz D, Clark DC, Thiele EA. A karate program for improving self-concept and quality of life in childhood epilepsy: Results of a pilot study. Epilepsy Behav 2008;12: 61-5.

33. Eriksen HR, Ellertsen, B, Hestad, K. A. Physical exercise and epilepsy. In Mostofsky DL, Zaichkowsky LD, editors. Medical and Psychological Aspects of Sport and Exercise, Morgantown: Fitness Information Technology Inc; 2002, p. 149-56.

34. Arida RM, Guimaraes de Almeida AC, Cavalheiro EA, Scorza FA. Experimental and clinical findings from physical exercise as complementary therapy for epilepsy. Epilepsy Behav 2013; 26: 273-78.

35. Allen-Collinson J, Hockey J. 'Working out' identity: Distance runners and the management of disrupted identity. Leisure Stud 2007;26(4): 381-98. 
36. Heise J, Buckworth J, McAuley JW, Long L, Kirby T. Exercise training results in positive outcomes in persons with epilepsy. Clin Exerc Physiol 2002; 4(2): 79-84.

37. Arida RM, Scorza FA, Terra VC, Scorza C, de Almeida A, Cavalheiro EA. Physical exercise in epilepsy: What kind of stressor is it? Epilepsy Behav 2009;16: 381-87.

38. Jacoby, A. Stigma, epilepsy, and quality of life. Epilepsy Behav 2002;3(6): 10-20.

39. Kaufman KR, Kaufman ND. Epileptic Disord 2013;15(2):211-5 